\title{
Influence of the cutting parameters on the workpiece temperature during face milling
}

\author{
Lukasz Nowakowski ${ }^{1,}$, Michal Skrzyniarz ${ }^{1}$, Edward Miko ${ }^{1}$, Jakub Takosoglu ${ }^{1}$, Slawomir Blasiak $^{1}$, Pawel Laski $^{2}$, Gabriel \\ Bracha $^{2}$, Dawid Pietrala ${ }^{2}$, Jaroslaw Zwierzchowski ${ }^{2}$ and Malgorzata Blasiak ${ }^{3}$ \\ ${ }^{1}$ Chair of Mechanical Engineering and Metrology, Kielce University of Technology; Aleja Tysiąclecia Państwa Polskiego 7; 25-314 \\ Kielce; Poland \\ ${ }^{2}$ Faculty of Mechatronics and Mechanical Engineering, Department of Automation and Robotics, Kielce University of Technology, \\ Aleja Tysiaclecia Panstwa Polskiego 7, 25-314 Kielce, Poland \\ ${ }^{3}$ Department of Mechanics, Kielce University of Technology; Aleja Tysiąclecia Państwa Polskiego 7; 25-314 Kielce, Poland
}

\begin{abstract}
This thesis presents the outcome of experimental research of the impact of changes in cutting speed and volume of material processed during a face milling process on the temperature of the processed object made of copper of M1Ez4 class. Measurement of the temperature of the processed object was conducted in six points with K-type thermocouples. The theoretical amount of released heat per unit of time for particular parameters of machining was also calculated.
\end{abstract}

\section{Introduction}

During the mechanical processing of the machining process, over $99.5 \%$ of machining work is transformed into heat [1-3]. The amount of heat is released per unit of time, so the stream of heat corresponds to the approximate machining power [3-6]. The source of heat in the machining process includes: work of plastic deformations and division of material (formation of chips), friction on the contact surface and rake face [211]. Heat generated as a result of the machining process is dissipated through chips, acquired by the tool and the processed material, and raised up to the ambient atmosphere or acquired by the cooling and lubricating liquid [4-6]. In the case of ISO N materials - so nonferrous metals such as aluminum, copper, brass, etc. the percentage distribution of heat streams may amount to about $70 \%$ for the processed object, $20 \%$ for chips, and $2 \%$ for the cutting edge [12-14]. The uncontrolled temperature increase of the processed object may lead to a performance decrease of parts of machines, machine tools [15-19], and devices i.e. guides, proximity face seals, pneumatic valves [20-27], and precision devices used to control flying objects [28-30]. Increased temperature of the processed object during processing may lead to changes in the structure of the surface layer [31-33], decrease of processing accuracy [15-19], [34, 35] related to thermal expansion of the processed material, as well as its deformation [36, 37] resulting from uneven heating. Mistakes in performance of precision parts caused by uncontrolled heating of the processed object during face milling may result in improper operation of the device e.g. by faster wear of surfaces that work together, which may cause vibration and friction resistances [38 - 40].

\section{Methods}

The subject of studies was to determine temperature changes of the processed object during face milling of copper. The research was performed on samples made of M1Ez4 copper $(99.95 \% \mathrm{Cu})$ with six predrilled holes for thermocouples. The size and placement of holes has been presented in Fig. 1.

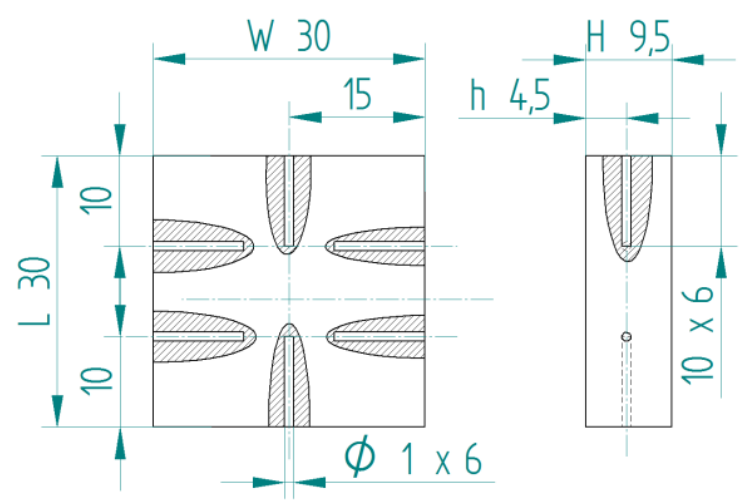

Fig. 1. View of workpiece

The process of face milling of $30 \times 30 \mathrm{~mm}$ surface of copper samples has been conducted on a vertical machining center AVIA VMC800 (fig. 2) with the usage of the cutting head R245-080Q27-12M manufactured by Sandvik Coromant with machining diameter of $\mathrm{D}_{\mathrm{c}}=80$ $\mathrm{mm}$, facilitated with 245-12T3M-PL4230 plates. Machining attempts have been conducted at two machining velocities $\mathrm{v}_{\mathrm{c}}=250$ and $375 \mathrm{~m} / \mathrm{min}$, at a fixed feed rate on the edge of $f_{z}=0.05 \mathrm{~mm} /$ tooth and fixed depth of cut of $a_{p}=0.5 \mathrm{~mm}$ for which the distance from thermocouples "h" and volume of the processed material

\footnotetext{
Corresponding author: lukasn@tu.kielce.pl
} 
were variable (table 1). Detailed parameters of machining have been presented in table 2 .

Table 1. Workpiece dimensions

\begin{tabular}{|c|c|c|c|c|c|}
\hline & $\begin{array}{c}\text { Length } \\
\text { L, mm }\end{array}$ & $\begin{array}{c}\text { Width } \\
\text { W, } \\
\text { mm }\end{array}$ & $\begin{array}{l}\text { Height } \\
\text { H, mm }\end{array}$ & $\begin{array}{c}\text { Distance } \\
\text { h, mm }\end{array}$ & $\begin{array}{l}\text { Workpiece } \\
\text { vol., } \mathbf{m m}^{3}\end{array}$ \\
\hline 1 & \multirow{6}{*}{30} & \multirow{6}{*}{30} & 9.5 & 4.5 & 8550 \\
\hline 2 & & & 9 & 4 & 8100 \\
\hline 3 & & & 8.5 & 3.5 & 7650 \\
\hline 4 & & & 8 & 3 & 7200 \\
\hline 5 & & & 7.5 & 2.5 & 6750 \\
\hline 6 & & & 7 & 2 & 6300 \\
\hline
\end{tabular}

Measurement of the temperature of the processed object was conducted through six K-type thermocouples with diameter of $1 \mathrm{~mm}$ placed in six holes of $10 \mathrm{~mm}$ depth distributed as in fig. 1. Fig. 3 presents the measurement station and the sequence of placing thermocouples in the sample.

Table 2. Parameters of machining

\begin{tabular}{|c|c|c|}
\hline Cutting speed & $\mathrm{v}_{\mathrm{c}}=250 \mathrm{~m} / \mathrm{min}$ & $\mathrm{v}_{\mathrm{c}}, 375 \mathrm{~m} / \mathrm{min}$ \\
\hline Spindle rotation & $\mathrm{n}=855 \mathrm{rpm}$ & $\mathrm{n}=855 \mathrm{rpm}$ \\
\hline Feed per tooth & \multicolumn{3}{|c|}{$\mathrm{f}_{\mathrm{z}}=0.05 \mathrm{~mm} / \mathrm{tooth}$} \\
\hline Feed rate & \multicolumn{2}{|c|}{$\mathrm{v}_{\mathrm{f}}=513 \mathrm{~mm} / \mathrm{min}$} \\
\hline Depth of cut & $\mathrm{a}_{\mathrm{p}}=0.5 \mathrm{~mm}$ \\
\hline Width of cut & $\mathrm{a}_{\mathrm{e}}=30 \mathrm{~mm}$ \\
\hline
\end{tabular}

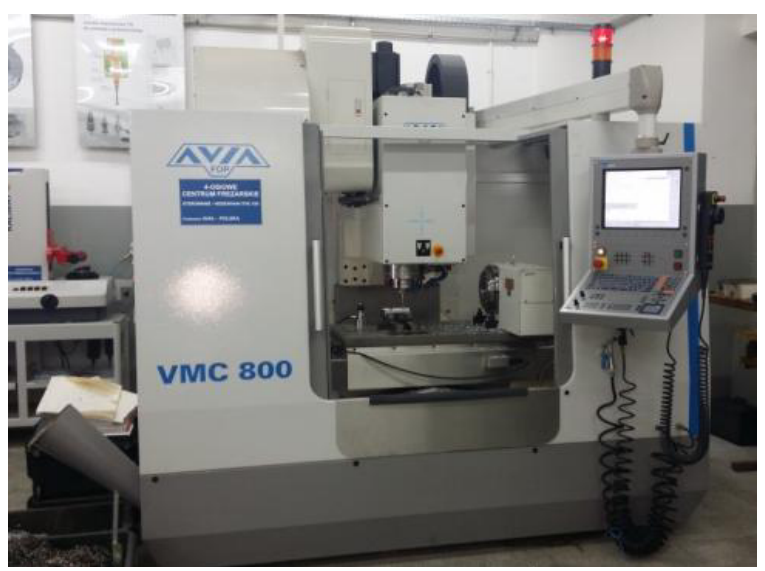

Fig. 2. View of vertical machining center AVIA VMC 800

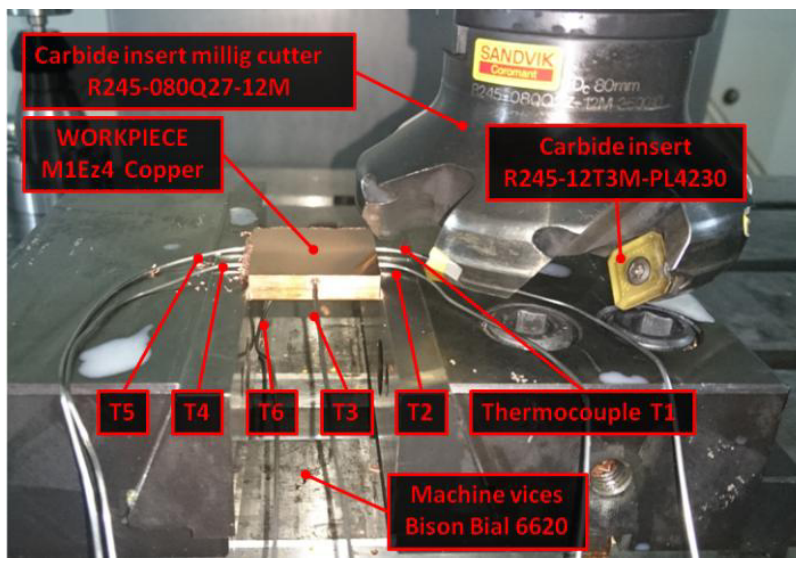

Fig. 3. Measurement station and the sequence of placing thermocouples in the sample.

\section{Calculations}

Total heat in machining released per unit of time (heat stream) corresponds to the approximate machining power and may be determined by the following formula:

$$
Q=F_{c} \cdot v_{c} W
$$

where: $F_{c}$ - machining force $N, v_{c}$ - cutting speed $\mathrm{m} / \mathrm{s}$.

Determination of the value of machining force $F_{c}$ may be conducted on the basis of a formula based on knowing the specific machining resistance $\mathrm{k}_{\mathrm{c}}$.

$$
F_{c}=A \cdot k_{c} \quad N
$$

where: A - cross sectional area of the machined layer $\mathrm{mm}^{2} \mathrm{~N}, \mathrm{k}_{\mathrm{c}}$ - specific machining resistance $\mathrm{N} / \mathrm{mm}^{2}$.

Specific machining resistance $\mathrm{k}_{\mathrm{c}}$ must be calculated depending on the average thickness of the machined layer $\mathrm{h}_{\mathrm{m}}$.

$$
k_{c}=\frac{k_{c 1.1}}{h_{m}{ }^{m}} \quad \mathrm{~N} / \mathrm{mm}^{2}
$$

where: $\mathrm{k}_{\mathrm{c} 1.1}$ - the value of specific resistance for the unit of thickness of the machined layer $\mathrm{N} / \mathrm{mm}^{2}, \mathrm{~h}_{\mathrm{m}}$ - the average thickness of the machined layer in $\mathrm{mm}, \mathrm{m}$ exponent.

The average thickness of chips $\left(\mathrm{h}_{\mathrm{m}}\right)$ for a simple cutting edge will be determined depending on:

$$
h_{m}=\frac{180 \cdot \sin \kappa_{r} \cdot a_{e} \cdot f_{z}}{\pi \cdot D_{\text {cap }} \cdot \arcsin \left(\frac{a_{e}}{D_{\text {cap }}}\right)} \mathrm{mm}
$$

where: $\kappa_{\mathrm{r}}$ - setting angle ${ }^{\circ}, \mathrm{D}_{\text {cap }}$ - the effective machining diameter to the actual machining depth in $\mathrm{mm}$.

The efficient machining diameter for the actual depth of machining and the specific setting angle is calculated depending on:

$$
D_{\text {cap }}=D_{c} \cdot \frac{2 \cdot a_{p}}{\tan \kappa_{r}} \mathrm{~mm}
$$

Input data and calculation results of total heat released per unit of time during face milling for specific conditions of machining have been presented in table 3 .

Table 3. Input data and calculation results

\begin{tabular}{|c|c|}
\hline Data & Results \\
\cline { 1 - 1 } $\mathrm{Dc}=80 \mathrm{~mm}$ & \multirow{2}{*}{$\mathrm{D}_{\text {cap }}=81 \mathrm{~mm}$} \\
\cline { 1 - 1 } $\mathrm{a}_{\mathrm{p}}=0.5 \mathrm{~mm}$ & \multirow{2}{*}{$\mathrm{h}_{\mathrm{m}}=0.034 \mathrm{~mm}$} \\
\cline { 1 - 2 } $\mathrm{\kappa}_{\mathrm{r}}=45^{\circ}$ & $\mathrm{k}_{\mathrm{c}}=1695.6 \mathrm{~N} / \mathrm{mm}^{2}$ \\
\cline { 1 - 2 } $\mathrm{f}_{\mathrm{z}}=0.05 \mathrm{~mm} /$ tooth & \\
\cline { 1 - 2 } $\mathrm{a}_{\mathrm{e}}=30 \mathrm{~mm}$ & $\mathrm{~F}_{\mathrm{c}}=42.39 \mathrm{~N}$ \\
\cline { 1 - 2 } $\mathrm{k}_{\mathrm{c} 1.1}=780 \mathrm{~N} / \mathrm{mm}^{2}$ & $\mathbf{Q}=\mathbf{1 7 6 . 3 4} \mathbf{W}$ \\
\cline { 1 - 2 }$=0.23$ & $\mathbf{Q}=\mathbf{2 6 4 . 9 4} \mathbf{W}$ \\
\hline $\mathrm{A}=0.025 \mathrm{~mm}^{2}$ &
\end{tabular}


As a result of conducted theoretical calculations, it has been determined that during face milling with a cutting head R245-080Q27-12M made of M1Ez4 copper, the amount of released heat per unit of time for machining velocity of $\mathrm{v}_{\mathrm{c}}=250 \mathrm{~m} / \mathrm{min}$ is $\mathrm{Q}=176.34 \mathrm{~W}$, while for $\mathrm{v}_{\mathrm{c}}$ $=375 \mathrm{~m} / \mathrm{min}-\mathrm{Q}=264.94 \mathrm{~W}$

\section{Results of experimental studies}

Figure 4 presents graphs for the change of temperature within the period recorded by 6 thermocouples during processing of the sample made of M1Ez4 copper with machining velocity of $v_{c}=250 \mathrm{~m} / \mathrm{min}$ for the distance of the tool from thermocouples at $\mathrm{h}=4 \mathrm{~mm}$. By analyzing results presented in figure 4 , it has been observed that the maximum temperature of the sample during the process of face milling was obtained for thermocouple no. 5 - it amounted $66.1^{\circ} \mathrm{C}$. In the case of thermocouple no. 1 , the maximum temperature was $58.6^{\circ} \mathrm{C}$, which was the lowest maximum value measured for all thermocouples. Table 4 presents a comparison of results for maximum temperatures recorded by individual thermocouples for various " $h$ " values of the tool distance from thermocouples.

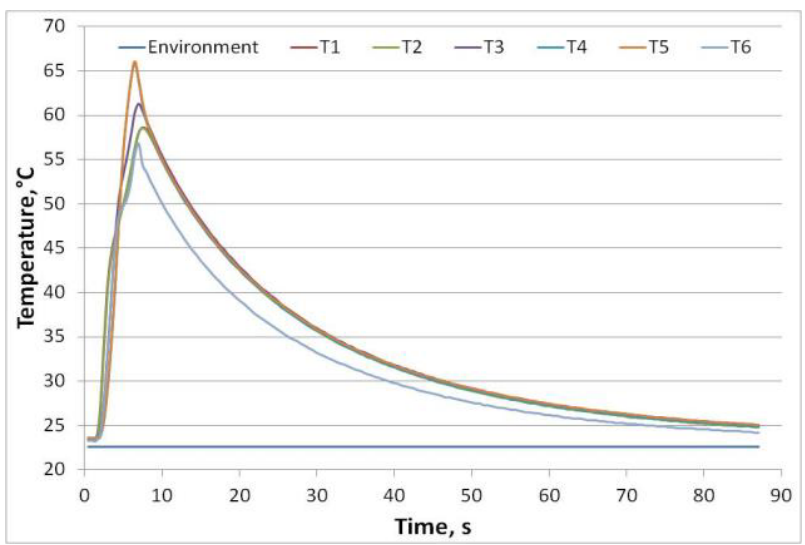

Fig. 4. Graphs of temperature during processing of the sample with cutting speed of $\mathrm{v}_{\mathrm{c}}=250 \mathrm{~m} / \mathrm{min}$ for the distance of the tool from thermocouples at $\mathrm{h}=4 \mathrm{~mm}$

Results presented in table 4 indicate uneven heating of the processed object during the process of face milling. For all samples, the highest temperatures were recorded in thermocouple 5 that was located in the left upper corner of the milled sample, so the cutting plates had to travel the longest distance in order to remove the material in that zone. The lowest values of the maximum temperature were recorded by thermocouple no. 1 that was located in the upper right corner. The only deviation was recorded during the 1 st attempt of machining, during which the maximum temperature of $47.1{ }^{\circ} \mathrm{C}$ was recorded for thermocouple no. 6 , which was caused by improper fixing of the thermocouple in the measurement hole.

Figure 5 presents charts of temperature changes of the copper sample that was face milled with machining velocity of $v_{c}=375 \mathrm{~m} / \mathrm{min}$ for the tool distance from thermocouples of $\mathrm{h}=4 \mathrm{~mm}$. The calculated amount of released heat per unit of time for machining velocity $\mathrm{v}_{\mathrm{c}}=375 \mathrm{~m} / \mathrm{min}$ was $\mathrm{Q}=264.94 \mathrm{~W}$. When analyzing results presented in figure 5 , it has been observed that the maximum sample temperature at $73.5{ }^{\circ} \mathrm{C}$ was obtained for the thermocouple no. 4 . On the other hand, the lowest maximum value was recorded for thermocouple no. 2, for which the maximum temperature was $60.4{ }^{\circ} \mathrm{C}$. Change of machining velocity from 250 to $375 \mathrm{~m} / \mathrm{min}$ caused an increase of $88.6 \mathrm{~W}$ the amount of released heat per unit of time, which led to a change of heating zones of the processed sample.

Table 4. Maximum temperatures recorded by individual thermocouples during processing of the sample with cutting speed of $\mathrm{v}_{\mathrm{c}}=250 \mathrm{~m} / \mathrm{min}$

\begin{tabular}{|c|c|c|c|c|c|c|}
\cline { 2 - 8 } \multicolumn{1}{c|}{} & \multicolumn{5}{|c|}{ Temperature, ${ }^{\circ} \mathbf{C}$} \\
\hline $\mathbf{h , ~ m m}$ & \multirow{2}{*}{ T1 } & \multirow{2}{*}{ T2 } & $\mathbf{T 3}$ & $\mathbf{T 4}$ & $\mathbf{T 5}$ & $\mathbf{T 6}$ \\
\hline $\mathbf{4 . 5}$ & 56.7 & 56.8 & 59.3 & 63.3 & 63.6 & 47.1 \\
\hline $\mathbf{4}$ & 58.6 & 58.6 & 61.3 & 65.9 & 66.1 & 56.8 \\
\hline $\mathbf{3 . 5}$ & 60.2 & 60.3 & 63.0 & 67.8 & 68.1 & 62.1 \\
\hline $\mathbf{3}$ & 61.6 & 61.7 & 64.7 & 69.9 & 70.3 & 62.9 \\
\hline $\mathbf{2 . 5}$ & 63.4 & 63.6 & 66.8 & 72.3 & 72.6 & 66.3 \\
\hline $\mathbf{2}$ & 64.6 & 64.8 & 68.3 & 73.8 & 74.2 & 63.2 \\
\hline
\end{tabular}

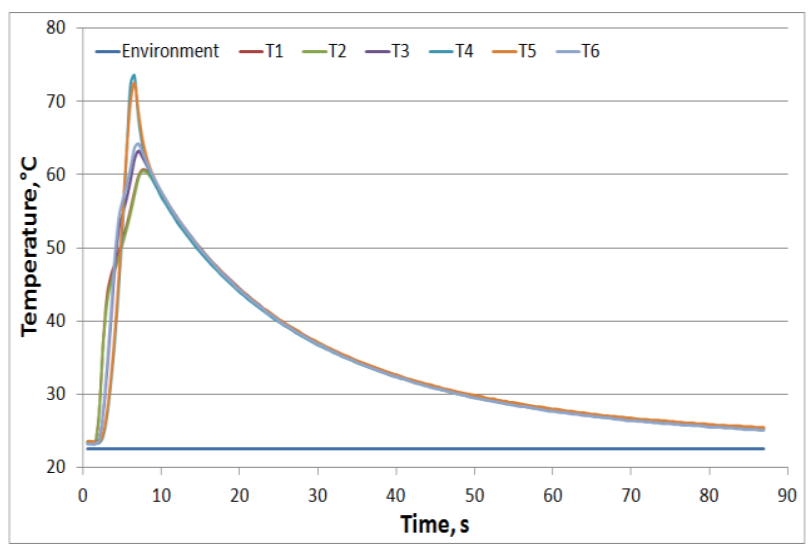

Fig. 5. Graphs of temperature during processing of the sample with cutting speed of $\mathrm{v}_{\mathrm{c}}=375 \mathrm{~m} / \mathrm{min}$ for the distance of the tool from thermocouples at $\mathrm{h}=4 \mathrm{~mm}$

Analogously to table 4, table 5 presents a comparison of results for maximum temperatures recorded by individual thermocouples for various " $\mathrm{h}$ " values of the tool distance from thermocouples.

Table 5. Maximum temperatures recorded by individual thermocouples during processing of the sample with cutting speed of $\mathrm{v}_{\mathrm{c}}=375 \mathrm{~m} / \mathrm{min}$

\begin{tabular}{|c|c|c|c|c|c|c|}
\cline { 2 - 7 } \multicolumn{1}{c|}{} & \multicolumn{7}{c|}{ Temperature, $^{\circ} \mathbf{C}$} \\
\hline $\mathbf{h , ~ m m}$ & T1 & T2 & T3 & T4 & T5 & T6 \\
\hline $\mathbf{4 . 5}$ & 58.90 & 58.60 & 61.20 & 71.40 & 70.20 & 62.40 \\
\hline $\mathbf{4}$ & 60.60 & 60.40 & 63.20 & 73.50 & 72.50 & 64.20 \\
\hline $\mathbf{3 . 5}$ & 62.30 & 62.00 & 64.90 & 75.80 & 74.80 & 66.00 \\
\hline $\mathbf{3}$ & 63.40 & 63.10 & 66.50 & 79.90 & 77.40 & 67.80 \\
\hline $\mathbf{2 . 5}$ & 65.10 & 64.80 & 68.40 & 81.60 & 79.80 & 69.70 \\
\hline $\mathbf{2}$ & 66.60 & 66.30 & 70.30 & 84.30 & 82.50 & 71.70 \\
\hline
\end{tabular}

In the case of all samples. the highest temperature was recorded for thermocouple no. 4 that was located in the 
left lower corner of the milled sample. while the lowest values of the maximum temperature were recorded by thermocouple no. 2 that was located in the right lower corner. When comparing data presented in tables 4 and 5 , it has been determined that the increase of machining velocity from 250 to $375 \mathrm{~m} / \mathrm{min}$ resulted in an increase of the maximum temperature of the machined object by $10.1{ }^{\circ} \mathrm{C}$.

Figure 6 presents the charts of temperatures recorded during the process of face milling on copper samples with two machining velocities for $\mathrm{h}=4.5 \mathrm{~mm}$. The continuous line stands for temperatures recorded for machining velocity of $250 \mathrm{~m} / \mathrm{min}$. while dotted line - for machining velocity equal $375 \mathrm{~m} / \mathrm{min}$.

When analyzing the chart presented in figure 6, we may notice that the increase of machining velocity results in an increase of the flow of released heat. which heats the processed object faster and to higher temperatures.

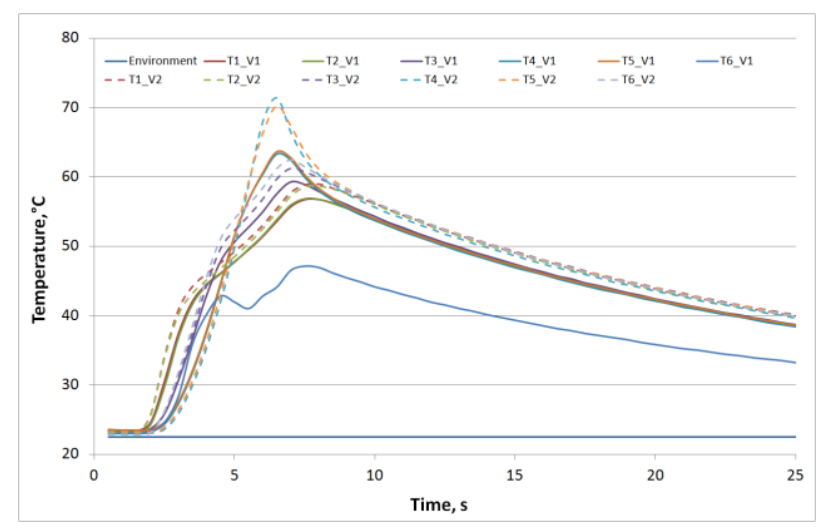

Fig. 6. Graph of maximum temperatures for different cutting speed

Table 6 presents example results of the impact of the change in machining velocity on the temperature of the processed object for $\mathrm{h}=4.5 \mathrm{~mm}$. Change of machining velocity from 250 to $375 \mathrm{~m} / \mathrm{min}$ caused an increase of $88.6 \mathrm{~W}$ the amount of released heat per unit of time. which in the case of the distance of the tool from thermocouples $\mathrm{h}=4.5$ resulted in an increase of the maximum temperature of the processed object by $\Delta T=$ $8.1{ }^{\circ} \mathrm{C}$ in comparison to processing at a lower machining velocity.

Table 6. Comparison of maximum temperature for different cutting speed

\begin{tabular}{|c|c|c|c|c|c|c|}
\cline { 2 - 7 } \multicolumn{1}{c|}{} & \multicolumn{6}{c|}{ Temperature, $^{\circ} \mathbf{C}$} \\
\hline $\mathbf{v}_{\mathbf{c}}, \mathbf{m} / \mathbf{m i n}$ & T1 & T2 & T3 & T4 & T5 & T6 \\
\hline $\mathbf{2 5 0}$ & 56.7 & 56.8 & 59.3 & 63.3 & $\mathbf{6 3 . 6}$ & 47.1 \\
\hline $\mathbf{3 7 5}$ & 58.9 & 58.6 & 61.2 & 71.4 & 70.2 & 62.4 \\
\hline $\boldsymbol{\Delta} \mathbf{T}$ & 2.2 & 1.8 & 1.9 & 8.1 & 6.6 & 15.3 \\
\hline
\end{tabular}

Figure 7 presents the comparison of lists of temperatures (maximum. average. and minimum) of milled samples depending on machining velocity and the distance of the tool from thermocouples. When analyzing data from figure 7 , it has been observed that together with the decrease of the "h" value of the tool distance from thermocouples. the maximum values of recorded temperatures were increasing. which also resulted from the decrease of volume of processed samples after each cycle of the tool, which has been presented in table 1 . For machining velocity equal $250 \mathrm{~m} / \mathrm{min}$, loss of material of $450 \mathrm{~mm}^{3}$ caused an increase of the maximum average temperature of the sample by $2.12^{\circ} \mathrm{C}$, while for $\mathrm{v}_{\mathrm{c}}=375 \mathrm{~m} / \mathrm{min}$ by $2.58{ }^{\circ} \mathrm{C}$.

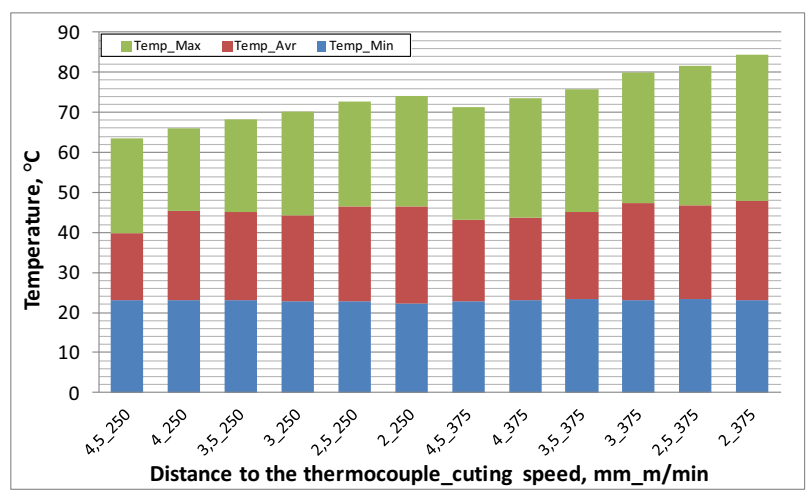

Fig.7. Comparison of temperatures (maximum, average, and minimum) of milled samples

\section{Summary}

Conducted research allowed to analyze the impact of changes in cutting speed and volume of material processed during a face milling process on the temperature of the processed object made of copper of M1Ez4 class.

Conducted research proves that:

1. Increased machining velocity during the process of face milling causes an increase of performance of the process itself, but also results in an increased amount of released heat per unit of time, which may lead to uncontrolled heating of the processed object to high temperatures.

2. The process of face milling with $\mathrm{v}_{\mathrm{c}}=250 \mathrm{~m} / \mathrm{min}$, $\mathrm{f}_{\mathrm{z}}=0.05 \mathrm{~mm} /$ tooth, $\mathrm{a}_{\mathrm{p}}=0.5 \mathrm{~mm}, \mathrm{a}_{\mathrm{e}}=30 \mathrm{~mm}$ led to heating of the processed object to a maximum temperature of $74.2^{\circ} \mathrm{C}$.

3. Increase of the machining velocity from 250 to 375 $\mathrm{m} / \mathrm{min}$ resulted in an increase of the maximum temperature of the processed object from $10.1{ }^{\circ} \mathrm{C}$ to $84.3^{\circ} \mathrm{C}$.

4. During the process of face milling, the processed object was heated unevenly.

5. Along with the decrease of the volume of processed samples and, consequently, of the "h" value of tool distances from thermocouples, the maximum values of recorded temperatures increased.

6. For machining velocity of $250 \mathrm{~m} / \mathrm{min}$. loss in material of $450 \mathrm{~mm}^{3}$ caused an increase of the average maximum temperature of the sample by $2.12{ }^{\circ} \mathrm{C}$. while for $\mathrm{v}_{\mathrm{c}}=375 \mathrm{~m} / \mathrm{min}-2.58{ }^{\circ} \mathrm{C}$. 


\section{References}

1. M. Bartoszuk, W. Grzesik, Edited by: Outeiro, Modelling Of Machining Operations Advan. Mat. Res. 223, 231 (2011)

2. W. Grzesik, M. Bartoszuk, P. Nieslony, Machining Science And Technology 9, (4), 529 (2005)

3. W. Grzesik, P. Nieslony, M. Bartoszuk,Trans. of the North Ameri. Manuf. Res. Inst. of Sme XXIX, 343 (2001)

4. S. Hożejowska, R. Kaniowski, M. E. Poniewski, Exper. Thermal and Fluid Science 78, 18 (2016)

5. S. Hożejowska, R. Kaniowski, M. E. Poniewski, Inter. J. of Num. Meth. for Heat \& Fluid Flow 24, (4), 811 (2014)

6. R. Pastuszko, R. Kaniowski, EPJ Web of Conferences (Proc. Int. Conf. Experimental Fluid Mechanics 2010) 25, 02019 (2012)

7. S. Blasiak, J. E. Takosoglu, P. A. Laski, J. Therm. Sci. Techn. 9, 2 (2014)

8. S. Blasiak, P. A. Laski, J. E. Takosoglu, Int. J. Heat Mass Tran. 57, 1 (2013)

9. S. Blasiak, C. Kundera, Procedia Eng. 39, 315 (2012)

10. S. Blasiak, A. Pawinska, Int. J. Heat Mass Transf. 90, 710 (2015)

11. S. Blasiak, C. Kundera, J. Bochnia, Procedia Eng. 39. 366 (2012)

12. W. Depczyński, R. Kazała, K. Ludwinek, K. Jedynak, Mat. 9 (7), 567, 1 (2016)

13. W. Depczyński METAL 2014 23rd Inter. Conf. on Metal. and Mat. 1219 (2014)

14.S. Spadło, P. Młynarczyk, W. Depczyński, Proceedings of 24th Inter. Conf. on Metall. and Mat. METAL 2015863 (2015)

15. L. Nowakowski, E. Miko, M. Skrzyniarz, Edited by Zolotarev I., Radolf V. Proceedings of 22nd International Conference on Engineering Mechanics 2016 (Academy of Sciences of the Czech Republic. 2016)

16. L. Nowakowski, M. Wijas, Edited by Zolotarev I., Radolf V. Proceedings of 22nd International Conference on Engineering Mechanics 2016 (Academy of Sciences of the Czech Republic. 2016)

17. E. Miko, L. Nowakowski, Procedia Eng. 39 (2012a)

18. E. Miko, L. Nowakowski, Procedia Eng. 39 (2012b)

19. S.Adamczak, E. Miko, F. Cus, Strojniski VestnikJour. of Mech. Eng. 55, (1), 45 (2009)

20. J.E. Takosoglu, Edited by Zolotarev I., Radolf V. Proceedings of 22nd International Conference on Engineering Mechanics 2016 (Academy of Sciences of the Czech Republic. 2016)

21. J.E. Takosoglu, P.A. Laski, S. Blasiak, G. Bracha, D. Pietrala, Meas. Cont. 49, 22016

22. P.A. Laski, J.E. Takosoglu, S. Blasiak, Rob Auton Syst.72, 59 (2015)

23. G.F. Bracha. Edited by Zolotarev I., Radolf V. Proceedings of 22nd International Conference on Engineering Mechanics 2016 (Academy of Sciences of the Czech Republic. 2016)

24. J.E. Takosoglu, P.A. Laski, S. Blasiak, Edited by Fuis V., Proceedings of 20th International
Conference on Engineering Mechanics 2014 (Brno University of Technology. Czech Republic. 2014)

25. J.E. Takosoglu, P.A. Laski, S. Blasiak, P. I. Mech. Eng. I-J. Sys. 226, 10 (2012)

26. P.A. Laski, Edited by Zolotarev I.. Radolf V. Proceedings of 22nd International Conference on Engineering Mechanics 2016 (Academy of Sciences of the Czech Republic. 2016)

27. D.S. Pietrala, Edited by Zolotarev I.. Radolf V. Proceedings of 22nd International Conference on Engineering Mechanics 2016 (Academy of Sciences of the Czech Republic. 2016)

28. I. Krzysztofik, Z. Koruba, J. of App. Math., Vol. 2014, 11 (2014).

29. I. Krzysztofik, Edited by Zolotarev I., Radolf V. Proceedings of 22nd International Conference on Engineering Mechanics 2016 (Academy of Sciences of the Czech Republic. 2016)

30.Z. Koruba, I. Krzysztofik, P. I. Mech. Eng. K-J. Multi-Body Dyn. 227, K1 (2013)

31. J. Zwierzchowski, Edited by Zolotarev I.. Radolf V. Proceedings of 22nd International Conference on Engineering Mechanics 2016 (Academy of Sciences of the Czech Republic. 2016)

32. D. Janecki, L. Cedro, J. Zwierzchowski, Metrology Meas. Sys. 22, 22015

33. D. Janecki, J. Zwierzchowski, L. Cedro. B. Pol. Acad. Sci-Tech. Sci. 63, 32015

34. P. Michalik. J. Zajac. M. Hatala. D. Mital. V. Fecova. Measur. 58, 416 (2014)

35. P. Michalik. J, Zajac, Manuf. Eng. 9 (4), 63, (2010)

36. M. Graba. J, of Theor. And Appl. Mech. 50, (1), 23,(2012)

37. M. Graba., J. of Theor. And Appl. Mech. 51, (2), 349 (2013)

38. L. Nowakowski, M. Miesikowska, M. Blasiak, Edited by Zolotarev I., Radolf V. Proceedings of 22nd International Conference on Engineering Mechanics 2016 (Academy of Sciences of the Czech Republic. 2016)

39. M. Blasiak, Edited by Zolotarev I., Radolf V. Proceedings of 22nd International Conference on Engineering Mechanics 2016 (Academy of Sciences of the Czech Republic. 2016)

40. M. Blasiak, R. Kotowski, Przeglad Elektrotechniczny. 85, 12 (2009) 